\title{
Editorial Introduction to
}

\section{Exploring Technology Upgrading of Emerging Economies: From 'Shifting Wealth I' to} 'Shifting Wealth II'?'

\author{
Slavo Radosevic ${ }^{2}$, Dirk Meissner ${ }^{3}$, Iciar Dominguez Lacasa ${ }^{4}$, Jutta Günther ${ }^{5}$ \\ Pre-printed version of paper published in Technological Forecasting \& Social Change, 2019, \\ https://doi.org/10.1016/j.techfore.2019.03.019
}

The initial opening of China and India coupled with the opening of the former socialist countries in the 1990 s led to the integration of $40 \%$ of the global labour force into the world economy, causing large-scale effects regarding market integration, catching up, and income distribution. This trend has been defined as 'Shifting wealth I' (OECD, 2015). However, today, there is some uncertainty as to whether this process will continue, i.e. whether emerging economies will continue their process of technological upgrading and move from efficiency to innovation-driven growth. Whether we will observe 'Shifting Wealth II' or the further growth of emerging economies will ultimately depend on whether the productivity growth of emerging economies will be associated with further upgrades in technology ${ }^{6}$. In addition, technology upgrading was, until recently at least, to some extent positively connected with the prevailing liberalized trade regime. Currently there are political developments around the world which represent a threat to the established trade system by way of increasing national protectionism which might impact future upgrading in one way or the other.

The rise of emerging and developing economies during the 1990s and the first decade of the $21^{\text {st }}$ century has increased their share in world GDP to over $50 \%$. This tipping point was

\footnotetext{
${ }^{1}$ We acknowledge excellent editorial assistance of Toby Law.

2 University College London, UK

${ }^{3}$ National Research University Higher School of Economics Moscow, Russia

${ }^{4}$ Technical University of Applied Sciences Wildau, Germany

${ }^{5}$ University of Bremen, Germany

${ }^{6}$ In continuation, for simplicity reasons we refer to both transition and emerging economies as emerging economies. These two groups of economies have become similar in many economic, technological and institutional features to the point that it is increasingly difficult to treat them as two distinctive groups. For discussion see Meyer and Peng (2016).
} 
reached in 2008 and denotes the landmark event in the long-term process of Shifting Wealth or in the ongoing change in the economic balance between developing/emerging and developed economies. Shifting Wealth has established emerging economies as a new category of countries in-between developed and developing economies and has led to an increased global integration in the areas of finance, production, and technology. It has led to considerable decreases in mass poverty, but also to new inequalities within economies.

We recognise that the convergence between advanced and emerging economies is a process driven by a variety of other factors (population growth, demand as shaped by income distributions and inequalities, technology advances in the developed world, global political economy, etc). However, we also recognise that technology upgrading is one of the major structural features of economies which help us separate long-term trends and drivers of growth from a variety of short- and medium-term cyclical factors that affect the process of convergence and which lead to sharp swings in forecasts and expectations.

OECD (2018) divides this period into three stages: the initial opening period (1990-2000), the period of pervasive convergence (2001-08) and the post-Global Financial Crisis period (2009>). Emerging economies grew faster than the high-income countries even during the severe financial crisis of the year 2008/2009. They were much less hit and experienced a much weaker slowdown than the high-income economies (Fagerberg and Srholec 2016). However, in recent years, this trend of "shifting wealth" from the "West" to the "South and East" has slowed down significantly and has been driven mainly by China and partly India (OECD, 2018).

Different factors and circumstances have been explored as reasons for this slowdown, such as lower commodity prices, harder access to financial markets, demographic and labour market factors, urbanisation, climate change, political conflicts and security (OECD 2017). This situation has been described as the middle-income trap (MIT), although definitions of MIT differ significantly across studies, especially concerning the suggested income thresholds (Glawe \& Wagner, 2016). Shift Wealth I to II seems to be part of the MIT which is perceived as a 'lock-in' state between the middle to high-income status. The MIT is a blockage in the structural transformation which cannot easily be explained. Some explain it with reference to mismatches between changes in the existing economic structure and supporting institutions 
(Aghion and Bircan, 2017) while others explain it as domestic cleavages among social groups that impede the coalition building required for institutional upgrading (Doner and Ross Schneider, 2016). Whatever the ultimate explanations of the situation, they have to do with blockages in technology upgrading. The middle-income trap denotes blockages in the structural transformation from production to technological capability, and in the transformation from secondary to high value-added tertiary sector activities

It seems that the sources of productivity growth in the "shifting wealth I" stage have been gradually exhausted as opportunities from labour reallocations and efficiency improvements through trade and investment liberalisation have become ever rarer. This has been compounded by decreasing productivity growth globally (Bloom et al. 2017, OECD 2015), and by the 'China effect' on many emerging and advanced economies. As the traditional growth paradigm of labour-intensive manufactured exports has reached its limits, the issue turns to what may be the new potential sources of growth which are capable of propelling emerging economies forward. Premature deindustrialisation deprives emerging economies of manufacturing as the primary driver of R\&D investments; they are left with services-which have very limited backward linkages with the rest of economy-as the basis for their longterm prosperity (Rodrik, 2016).

In this scenario, it is uncertain whether emerging economies will move from efficiency to innovation-driven growth. It therefore remains an open question whether we will observe a continuation of the shift from "wealth I" to "wealth II". It will ultimately depend on whether the productivity growth of emerging economies will be driven by technology upgrading (Radosevic and Yoruk 2017). This process is made more difficult as the focus of competition between and within value chains has moved towards innovation-driven competition.

The thematic issue of TFSC explores the issue of Shifting Wealth from the perspective of technology upgrading, which we define as increasing productivity based on improved technology capabilities.

This special issue assembles original research, mostly empirical and representing multiple methods of empirical research including quantitative as well as qualitative approaches, to 
better understand the ongoing processes of and efforts toward technology upgrading. Latin American, Asian as well as (Central) East European countries are looked at including micro, mezzo, and macro perspectives. The majority of papers in their draft form have been presented at the conference organised by the UCL Centre for Comparative Study of Emerging Economies held on $26-27^{\text {th }}$ June $2017^{78}$.. Selected papers have undergone the standard peer review procedure of which the most appropriate papers have been selected for this issue of TFSC.

The primary motivation for the thematic issue is to try to move forward research on technology upgrading. Technology upgrading as a research perspective builds on significant past work on technology accumulation in developing economies (for example Bell and Pavitt, 1993; Lall, 1992). Hence, technology upgrading represents a rejuvenation and an adaptation of this research program in the context of an environment of globalised economies where dominant matrices and frameworks are oriented towards frontier economies (Radosevic and Yoruk, 2015). The dominant metric of relevance for technology upgrading like the Global innovation index and the EU Innovation Union Scoreboard or Global Competitiveness Index capture but a part of the complexity of technology upgrading. These metrics do not capture a range of facets of technology activities which are present in emerging economies like production capability, firm-level organisational capabilities, low value-added activities in high-tech sectors, the diffusion of management practices, engineering activities, etc.

The changing nature of industries driven by the deployment of ICTs is changing the patterns of technology upgrading at the industry level and factors that affect the creation of technology capabilities at the firm level. These processes are increasingly becoming dependent on external sources of knowledge, but we do not have an articulate understanding of the main stylised facts of these processes. These insights are rather valuable if we are to better understand outcomes observed at the macro-level through country-level indicators.

\footnotetext{
7 https://www.ucl.ac.uk/ssees/events/2017/jun/exploring-technology-upgrading-emerging-and-transitioneconomies

${ }^{8}$ Also, papers presented at the conference on "Innovation in Emerging Economies" held on 13-14th July 2017 in Berlin organised by the Copenhagen Business School, National Research University - Higher School of Economics, Technical University Berlin, and University of Bremen have been considered as submissions relating to this issue
} 
Technology upgrading of emerging economies is inextricably linked to the modes of their integration in global value chains (GVC). According to some views, the integration in GVC enables economies to be plugged into global knowledge exchange and thus renders obsolete place-based policies (Baldwin, 2016). Another view is that integration into GVC limits emerging economies to improvements in production capability, turning them into labour intensive 'assembly economies'. Irrespective of differences in views, our understanding of the opportunities, limitations, and determinants of GVC-based upgrading is quite limited.

In the rest of this paper, we reinterpret key messages derived from nine individual papers which fall within the overall theme of the overarching issue at hand and draw conclusions presenting a common denominator of the selected papers. In our conclusion, we outline issues for further research.

A strong underlying theme in all papers is the importance of the interactivity between a country's technological capability and organisational/institutional capabilities. In that respect, the thematic issue represents a clear departure from the past literature, which was firmly focused on the processes of firm-level technology accumulation. The organisational and institutional dimension of technology upgrading emerges not only at the inter-firm level but also at the firm level.

Choung and Hwang (this volume) explore the issue of the prevailing institutional capabilities for technology upgrading in the Korean nuclear industry. They highlight the crucial role of regulatory innovation and how institutional lock-in can block regulatory innovations. Their evidence shows that in the early stage of the catch-up period, the regulatory framework is vital while further technology transition in the post-catch-up period requires regulatory innovation. Their research is probably the first of its kind that treats the temporal agenda underlying technology capability and regulatory innovation for emerging economies. It shows that the co-evolution of technology and regulation (standards, IPR management, project financing, certification and testing) is critical for the upgrading process.

Bernat and Karabag (this volume) explore the issue of technology upgrading at the advanced stages of catching up in the cases of two high profile Brazilian firms. A central issue is how 
to align the processes of technology upgrading with the respective firm's strategy. In large organisations, there is a multiplicity of visions and work goals related to firm strategy, market changes, and technology trends that should be continuously settled and aligned. These two success cases show that monitoring, strategizing, aligning, and learning are significant organisational activities for firms in emerging economies along with their paths of technology upgrading and innovation. In a nutshell, their evidence points to the importance of organisational processes and capabilities for high-end technology upgrading in emerging economies' firms.

Fischer, Rücker Schaeffer, and Vonortas (this issue) examine the evolution of universityindustry collaboration in Brazil from a technology upgrading perspective. They show that industry-university links have deepened, but that they are also still confined to problemsolving, and that they are domestic market oriented and not yet strategic. According to them, research-oriented universities are increasingly involved in technology upgrading processes and linkages with the private sector have strengthened. However, connections with international value chains are found lacking, which probably reflects the overall domestic market orientation of the Brazilian innovation system. In a nutshell, their research shows that technology upgrading is inter-organisational activity and that the strategic role of universities is closely linked to the technology upgrading process in the business sector. It seems that university-industry links reflect the current degree and orientation of technology upgrading in the Brazilian business sector. In that respect, this paper shows that the opportunities for university-industry collaboration cannot be understood outside of the context of the country's technology upgrading.

The systemic or inter-organisational nature of technology upgrading is explored in the case of Bangladesh's mobile telephone service sector. This sector represents the opposite end of the technology spectrum when compared to Brazilian industry-university links, which are focused on R\&D and patenting. A Bangladeshi case study by Dey, Babu, Rahman, Mishra, and Dora (this issue) examines technology acquisition and upgrading activities in the context of the mobile telephone industry in Bangladesh. As a response to local demand, SMEs offer a variety of mobile phone services, including repairing hardware, providing spare parts, and troubleshooting software. This is intriguing as these services are not offered by mobile operators or providers and Bangladesh does not have adequate formal vocational 
institutes/programmes for aspiring engineers/technicians. Hence, the development of skills and dissemination of knowledge in the smartphone repair and troubleshooting sector took place through informal apprenticeships and peer to peer support. The smartphone market has led to the development of a number of local apps in ride-hailing, food delivery, battery recharging, financial services, medical services, languages, and shopping. There is also a local version of Uber but for motorbike-based ridesharing and delivery.

What has here emerged organically is a local ecosystem upheld by the mutual support and cooperation among NGOs, SMEs, large local firms and multinationals, and government institutions. The authors show that technology upgrading has been achieved despite the absence of prerequisites like local formal vocational institutes. Also, the focus in this process is the marketplace rather than firms' mobile operators or smartphone providers. Similar to other papers on this issue (Fischer et al; Choung and Hwang), improved technology use and technology upgrading has been achieved by means of the emerging ecosystem where actors are involved in the joint co-creation of value through the use, adaptation, and upgrading of technology.

The topic of technology upgrading through global value chains has been one of the critical issues in the research on technology and globalisation. Deniz Yoruk's paper in this issue represents a significant contribution to this literature in several respects. Based on the case of the Polish clothing industry, she shows that functional upgrading is not an automatic and natural result of being inserted in GVC and global production networks (GPNs). By going beyond only GVC driven learning, she explores other networks and the internal dynamics of technology upgrading. This led to a new and significant result which shows that the GVC and learning by networking impede managerial upgrading, which is a prerequisite for functional upgrading. In a nutshell, the primary stimuli for functional upgrading are the existing internal dynamics of, managerial upgrading which represents a threshold capability that does not develop through GVC linkages. In this respect, her research justifies empirically why Radosevic and Yoruk (2018) treat international links as moderating component of technology upgrading framework rather than linear and additive component.

Along similar lines to Yoruk, Dinar Kale (this issue) shows how Indian pharma companies in the area of biosimilars pharmaceuticals have managed to couple global knowledge flows with 
local technology efforts. The paper explores their path of upgrading from small molecules' generics to biosimilars, which represents an up-grading of Indian firms' capabilities throughout the production process, starting from an upstream expansion of the knowledge base and a re-orientation of $R \& D$ toward a downstream enhancement of regulatory and marketing capabilities in emerging and advanced country markets. As a result, Indian pharma companies producing biosimilars are at similar stages of product development as are global MNEs. This process has been driven by accumulated capabilities in small molecules generics, by internationalisation through the hiring of overseas specialists, outward FDI and marketing collaboration with MNEs. While the mechanisms of interaction between foreign and local partners are entirely different, both Yoruk's and Kale's papers in this issue show that being merely plugged into GVC does not suffice for deeper technology upgrading.

The novelty of technology upgrading in the contemporary context is that the development and diffusion of advanced manufacturing technologies (AMT) can modify the patterns of upgrading. Our understanding of these issues is still very rudimentary. Andrea Szalavetz explores this issue in the context of Hungarian manufacturing subsidiaries. She explores how the implementation of Industry 4.0 affects capability development and her case studies provide very valuable new insights with far-reaching implications for patterns and mechanisms of technology upgrading. First, she argues that the implementation of AMT will lead to blurring boundaries between production, technology, and R\&D capabilities. In effect, this will lead to blurring boundaries between knowledge using and knowledge changing capabilities, which in the past were relatively autonomous categories. Instead, Szalavtez points to the emergence of 'technology production capabilities'. Augmented production capabilities are extended into planning, control, maintenance, inventory, and energy management. The deployment of $A M T$ is $R \& D$ intensive and leads to the development of production capabilities, which is one of the factors that can explain the relatively limited 'reshoring' of production capacities from Asia back to the 'North'.

The technology upgrading framework developed by Radosevic and Yoruk (2018) aims to measure different dimensions of technology upgrading and intentionally ignores the role of 
institutions in this process. It explicitly leaves this important dimension out of its analytical scope, which is focused solely on the outcomes of technology upgrading. Dutrenit, Natera, Anyul, and Vera-Cruz paper (this issue), take the opposite stance and develop metrics of technology upgrading which explicitly links patterns of technology capability accumulation to the development and institutional profiles of Latin American economies. They develop a conceptual and measurement framework to capture 'the techno-economic and the sociopolitical spheres' of Latin American economies and how they co-integrate. Based on the results of a co-integration analysis they classify Latin American economies based on the relationships between socio-political and techno-economic dimensions. Despite limited and conventional indicators being used, they have developed a very relevant hypothesis regarding the relationship between socio-political regimes and regimes of technology accumulation. In that respect, they are probably the first to try to quantitatively depict different patterns of the political economy of technology accumulation. In that respect, they have broadened the technology upgrading framework to include the development profiles of distinct regimes of technology accumulation. It is pioneering work whose value lies in generating exciting propositions which merit further research. Unlike the neutral socio-political system of the innovation perspective, their approach tries explicitly to integrate firm innovation activities with income distribution and social issues. This is a welcome contribution as innovation studies rarely venture into distributional issues and are confined to exploring only the creation of innovation rents, not how they are shared.

Yoruk's and Kale's papers in this issue point to the critical role of the interaction between GVCs and endogenous technology activities. Also, the innovation studies literature shows that the coupling of domestic technology efforts and technology transfer activities is key to technology upgrading and catching up in general (Radosevic, 1999). Based on this, we would expect the interaction between these two areas to be the central focus of innovation policy. However, we usually find in practice that these policy areas are either entirely separate, very weakly linked, or operate as substitutes. In that context, Sandrine Kergroach's contribution in this issue is unique and one of the first attempts to give us systematic evidence on the orientation of innovation policies on GVCs and technology upgrading. The paper is a crosscountry comparison based on the European Commission/OECD Science, Technology and Innovation Policy (STIP) Database, which monitors the "major national policy initiative" of 
fifteen countries with large science, technology, and innovation (STI) systems but different structural features and degrees of maturity. This evidence enables Sandrine to explore how technology upgrading policy is linked to GVC policy. Her research results provide several critical new insights. First, all analysed countries have FDI/GVC policies but much fewer technology upgrading policies. The most common instruments for the promotion of GVC/FDI are financial instruments. Second, countries with backward linkages tend to focus on enhancing these linkages while those with forward linkages tend to include more technology upgrading policies. Third, institutional and governance requirements for technology upgrading are higher than for GVC policies. These initial insights provide us with a better understanding of the 'morphology' of technology upgrading policies, but they also lead to new questions about policy mixes or the relationships between GVC and upgrading policies. The complementary or substitutive nature of GVCs and technology upgrading policies merits further attention. This research is the first that provides a mapping of these two policy dimensions and rich taxonomic evidence relating to different policy profiles.

Overall, based on selected papers, we can derive three conclusions as to the nature of technology upgrading in the context of the transition from Shifting Wealth to Shifting Wealth II.

First, when compared to the past literature on technology capability accumulation, these papers accord much greater importance to organisational capabilities and interorganisational relationships in technology upgrading. They all show that individual skills by themselves, however essential (especially in the context of AMT), do not suffice for technology upgrading without organisational (Bernat and Karabag) or inter-organisational capabilities (Choung and Hwang; Dey et al.; Fischer et al.). High tech education is critical, but it seems that, without organisational capabilities, these investments may not translate into economic benefits. Among organisational capabilities and in the context of international networks, the importance of managerial capabilities is evident (Yoruk). As sectors upgrade technologically, their inter-organisational capabilities need to be more diverse and include also institutional regulatory capabilities (Korean nuclear industry), or a familiarity with global regulatory issues (Indian pharma biosimilars). In cases like the Bangladeshi mobile telephone industry, inter-organisational capabilities have emerged spontaneously through a bottom-up 
process while in the case of Brazilian university-industry links, they are the outcome of a gradual long-term interaction between two sides. Last but not least, the introduction of AMT changes not only the nature of organisational capabilities but possibly also the nature of production and technological capabilities (Szalavetz) in ways which we still cannot fully grasp.

Second, technology upgrading as it progresses becomes a more systemic issue or rather it becomes the issue of coordinating a variety of agents involved in these processes. This increased need for interactivity is visible in different ways in different cases. The Korean nuclear industry demonstrates the need for the co-creation of regulation. The introduction of AMT increases the need for connectivity not only within firms but equally across their supply chains and knowledge networks (Szalavetz). The Brazilian university-industry links and the Bangladeshi mobile sector also demonstrate the crucial role of ecosystems or groupings of related firms and organisations in understanding the dynamics and limits of technology upgrading. The interactions between emerging market firms and foreign partners, or between GVC and FDI are specific in the sense that production-only integration does not lead to technology integration or integration into knowledge changing activities. Technology integration will take place only after emerging economies' firms build endogenous managerial and other capacities to engage in technology upgrading closer to the frontier (Yoruk; Kale). Overall, we can tentatively conclude that technology upgrading in the Shifting Wealth II stage will depend much more on improvements in connectivity and in the industrial ecosystem.

Third, two new areas of research within the technology upgrading perspective are the political economy of technology upgrading (Dutrenit et al.), and the mapping of technology upgrading policy activities and their interaction with GVC policies (Kergroach). Both issues are fraught with methodological challenges, but they also open two significant new research directions.

The selected papers by no means exhaust all new potential directions for research within the technology upgrading perspective. The limitations of these thematic issues are, firstly, that we have not addressed the issues of inclusive innovation and its impact on technology upgrading and, secondly, the impact of structural change (services, premature industrialisation) on technology upgrading and, thirdly, how green innovation impacts technology upgrading. However, the selected papers do represent signature contributions in 
our understanding of technology upgrading and we hope that readers will recognise the novelty of individual contributions.

\section{Acknowledgement}

Dirk Meissner's contribution to this article and Special Issues was prepared within the framework of the Basic Research Program at the National Research University Higher School of Economics (HSE) and supported within the framework of a subsidy by the Russian Academic Excellence Project '5-100'.

\section{References}

Aghion, Philippe; Bircan, Cagatay (2018): The Middle-Income Trap from a Schumpeterian Perspective. LSE Research Paper Series 01/2017.

Baldwin, Richard (2016) The Great convergence, Information technology and the New Globalization, Harvard University Press, Harvard MA.

Bell, M. \& Pavitt, K., 1993, "Technological Accumulation and Industrial Growth: Contrasts between Developed and Developing Countries", Industrial and Corporate Change, vol. 2, no.2, pp. 157-210.

Bloom, Nicholas; Jones, Charles I.; van Reenen, John; Webb, Michael (2017): Are Ideas Getting Harder to Find? In National Bureau of Economic Research. Available online at https://www.nber.org/papers/w23782.pdf.

Doner, Richard F.; Schneider, Ben Ross (2016): The Middle-Income Trap. More Politics than Economics. In World Politics 68 (4), pp. 608-644. DOI: 10.1017/S0043887116000095.

Fagerberg, J.; Srholec, M. (2016): Global dynamics, capabilities and the crisis. In: Journal of Evolutionary Economics, 26, 765-784. 
Glawe, Linda; Wagner, Helmut (2016): The Middle-Income Trap. Definitions, Theories and Countries Concerned-A Literature Survey. In Comp Econ Stud 58 (4), pp. 507-538. DOI: 10.1057/s41294-016-0014-0.

Günther, Jutta (2015): Innovation. In Jens Hölscher, Horst Tomann (Eds.): Palgrave Dictionary of Emerging Markets and Transition Economics. Insights from Archival Research. Basingstoke: Palgrave Macmillan, pp. 360-371.

Hölscher, Jens; Tomann, Horst (Eds.) (2015): Palgrave Dictionary of Emerging Markets and Transition Economics. Insights from Archival Research. Basingstoke: Palgrave Macmillan. Available online at http://gbv.eblib.com/patron/FullRecord.aspx?p=4082209.

Lall Sanjaya (1992) Technological Capabilities and Industrialization, World Development, Vol. 20, No. 2, pp. $165-186,1992$

Meyer, Klaus E.; Peng, Mike W. (2016): Theoretical foundations of emerging economy business research. In Journal of International Business Studies 47 (1), pp. 3-22. DOI: 10.1057/jibs.2015.34.

OECD (2010): Shifting wealth. Paris: OECD (Perspectives on global development, 1.2010).

OECD (2015): The Future of Productivity. Paris: OECD Publishing,. Available online at https://doi.org/10.1787/9789264248533-en.

OECD (2017): Beyond Shifting Wealth Perspectives on Development Risks and Opportunities from the Global South. Perspectives on Development Risks and Opportunities from the Global South: OECD Publishing. Available online at https://books.google.de/books?id=vfCGDgAAQBAJ.

OECD (2018) Perspectives on Global Development 2019. Rethinking Development Strategies, OECD, Paris. 
Radošević, Slavo (1999): International technology transfer and catch-up in economic development. Cheltenham, UK: Elgar.

Radošević, Slavo; Yoruk, Esin (2016): Why do we need a theory and metrics of technology upgrading? In Asian Journal of Technology Innovation 24 (sup1), pp. 8-32. DOI: 10.1080/19761597.2016.1207415.

Radošević, Slavo; Yoruk, Esin (2018): Technology upgrading of middle income economies. A new approach and results. In Technological Forecasting and Social Change 129, pp. 56-75. DOI: 10.1016/j.techfore.2017.12.002.

Rodrik, Dani (2016) Premature deindustrialization, J Econ Growth (2016) 21:1-33, DOI $10.1007 / \mathrm{s} 10887-015-9122-3$ 